\title{
Overuse of Cardiac Troponin Among Hospitalized Patients: A Cohort Study of Biomarker "Superusers"
}

\author{
Sean M. Taasan · David E. Winchester (D)
}

Received: June 9, 2020 / Published online: July 16, 2020

(C) The Author(s) 2020

Keywords: Acute coronary syndrome; Medical overuse; Troponin

\section{Key Summary Points}

The value of repeated measurements of cardiac troponin following the diagnosis of acute myocardial infarction (AMI) is unclear.

We investigated patterns of care among patients who underwent $\geq 20$ troponin assays during hospitalization.

The results of the analysis showed that repeated measurement of troponin was often encouraged by consultant cardiologists, despite a low rate of AMI and many patients being ineligible for coronary angiography.

Consultant cardiologists should not indiscriminantly recommend potentially wasteful laboratory assays.

Digital Features To view digital features for this article go to https://doi.org/10.6084/m9.figshare.12624167.

S. M. Taasan

University of Florida College of Medicine,

Gainesville, FL, USA

\section{INTRODUCTION}

Cardiac troponin assays are an essential test for evaluating patients with suspected acute coronary syndrome and provide necessary information to make a diagnosis of acute myocardial infarction (AMI) [1]. Serial measurements allow clinicians to determine the pattern of troponin, which can help distinguish between AMI and troponin elevation secondary to other conditions [2]. Concerns about the overuse of troponin assays have been previously raised in the literature [3]. In a prior investigation at our institution evaluating troponin use, we observed an exceptionally high number of assays had been performed on some patients during a single hospital stay [3]. That observation led us to conduct a descriptive study of the patients who had the highest number of troponin assays ordered for them, patients that we refer to as "superusers". To better understand the patterns of care associated with these encounters, we reviewed the medical records of a sample of patients on whom a large number of

\section{E. Winchester ( $\square)$}

Division of Cardiovascular Medicine, Department of Medicine, College of Medicine, University of Florida, Gainesville, FL, USA

e-mail: david.winchester@medicine.ufl.edu

D. E. Winchester

Malcom Randall Veterans Affairs Medical Center, Gainesville, FL, USA 
troponin assays had been performed during a single hospitalization.

\section{METHODS}

This was a single-center study conducted at an academic tertiary care hospital. Data were retrieved for all patients hospitalized between 2012 and 2015 on whom at least one troponin assay had been performed. All tests assayed for troponin $T$ (Roche Diagnostics, Indianapolis, IN, USA), with a reference range of $<0.03 \mathrm{ng} /$ $\mathrm{mL}$. All patients who had $\geq 20$ troponin T assays ordered within a single encounter were identified as "superusers" for this investigation. The cutpoint of 20 was chosen based on the frequency distribution of assays per patient in order to balance comprehensiveness with feasibility of detailed chart reviews. Data were extracted from a review of medical records, including clinical history, demographics, comorbidities, and outcomes.

This investigation was approved by the University of Florida Institutional Review Board-01 (protocol number 201501010) and conformed with the Helsinki Declaration of 1964, as revised in 2013. The need to obtain informed consent was waived.

\section{RESULTS}

Of the 43,063 inpatient encounters featuring at least one troponin assay, $0.12 \%(n=51)$ were identified as superusers. The mean (standard deviation) age of the patients was 59.9 (20.0) years, and the mean length of stay was 30.8 (18.8) days. Of these patients defined as superusers, all had at least one elevated troponin value, and 34 were men (67\%). The baseline characteristics of superusers are described in Table 1.

Of these 51 encounters, almost all patients $(n=47)$ had cardiology consultations; in approximately one-half of these patients $(n=25)$ the result of the cardiology consult was a recommendation for trending troponins (Table 2). In none of the superusers did repeated measures of troponin significantly alter the
Table 1 Baseline characteristics among troponin superusers $(n=51)$

\begin{tabular}{ll}
\hline Basic demographics & Values \\
\hline Age (years) & $59.9 \pm 20$ \\
Length of stay (days) & $30.8 \pm 18.8$ \\
Body mass index $\left(\mathrm{kg} / \mathrm{m}^{2}\right)$ & $28.89 \pm 7.19$ \\
Male & $34(67 \%)$ \\
Hypertension & $31(61 \%)$ \\
Diabetes mellitus & $25(49 \%)$ \\
Acute kidney injury & $10(20 \%)$ \\
Chronic kidney disease & $14(27 \%)$ \\
Coronary artery disease & $25(49 \%)$ \\
\hline
\end{tabular}

Values are presented as the mean \pm standard deviation or as the the number of patients with the percentage in parenthesis, as appropriate

"Superusers" in this investigation were defined as patients who had $\geq 20$ troponin $\mathrm{T}$ assays (Roche Diagnostics, Indianapolis, IN, USA) ordered within a single encounter

management plans. Only 29 patients were diagnosed with a myocardial infarction (MI); the remainder were diagnosed with acute myocardial injury. In 12 of these encounters, these patients were documented as not being candidates for invasive angiography due to either comorbidities or personal preferences.

\section{DISCUSSION}

While following the trend of troponins is a common response to suspected cardiac events, clinicians should only do so if they anticipate the results might alter how they manage the patient. In our sample of troponin "superusers," none of the patients experienced a change in their care due to the results of the assays. While formal criteria for the appropriate use of troponin assays have not been pursued by any professional cardiology societies, the lack of impact on care plans of the results from these assays suggests that for the population we studied, ordering a large number of troponin assays could be considered low value care. 
Table 2 Outcomes and observations among the 51 troponin superusers

\begin{tabular}{lc}
\hline Outcomes and observations & $n(\%)$ \\
\hline Outcomes & $29(57 \%)$ \\
MI diagnosed during encounter & $14(27 \%)$ \\
Death & $42(82 \%)$ \\
No procedure & $14(27 \%)$ \\
Catheterization & $5(10 \%)$ \\
PCI & $1(2 \%)$ \\
CABG & $47(92 \%)$ \\
Observations & $25(49 \%)$ \\
Cardiology consult performed & $5(10 \%)$ \\
Cardiology recommended trending troponins \\
Multiple suspected cardiac events during & $12(24 \%)$ \\
encounter & $4(8 \%)$ \\
Not candidate for invasive angiography & \\
Peri-operative MI/demand ischemia & \\
Post-transplant patient & \\
\hline
\end{tabular}

$C A B F$ Coronary artery bypass grafting, $M I$ myocardial infarction, $P C I$ percutaneous coronary intervention

Furthermore, a substantial portion of the "superusers" were never diagnosed with MI, suggesting that any elevation in their troponin level was chronic. For patients who are not candidates for invasive procedures (whether due to significant comorbidities or the patient's own documented preferences), trending troponins that are already known to be elevated will likely not change the course of care.

Troponin elevation has been shown in numerous settings to be a poor prognostic indicator, but that risk can be ascertained without repeated measurements of troponin. Facilities may need to reconsider how troponin assays can be ordered when newer high-sensitivity troponin assays become available. These new assays detect troponin in the majority of a healthy population with higher sensitivity for detecting MI, possibly at the cost of lower specificity [4]. Accordingly, concerns exist regarding whether this will lead to an increase in cardiovascular resource utilization.

\section{ACKNOWLEDGEMENTS}

Funding. This investigation was supported by an investigator-initiated grant from Roche Diagnostics and by NIH T35 Training Grant: T35-HL007489-33. The sponsors had no input on the design and conduct of the study; collection, management, analysis, and interpretation of the data; preparation, review, or approval of the manuscript; or decision to submit the manuscript for publication. No Rapid Service Fee was received by the journal for the publication of this article.

Authorship. All named authors meet the International Committee of Medical Journal Editors (ICMJE) criteria for authorship for this article, take responsibility for the integrity of the work as a whole, and have given their approval for this version to be published.

Disclosures. David E. Winchester has a former (> 36 months) consulting relationship with Roche Diagnostics. Sean M. Taasan has nothing to disclose.

Compliance with Ethics Guidelines. This investigation was approved by the University of Florida Institutional Review Board-01 (protocol number 201501010) and conformed with the Helsinki Declaration of 1964, as revised in 2013. The need to obtain informed consent was waived.

Data Availability. The datasets generated during and/or analyzed during the current study are not publicly available due to privacy limitations set by our IRB.

Open Access. This article is licensed under a Creative Commons Attribution-NonCommercial 4.0 International License, which permits any non-commercial use, sharing, adaptation, distribution and reproduction in any medium or format, as long as you give appropriate credit to the original author(s) and the source, provide a link to the Creative Commons licence, and indicate if changes were made. The images or other third party material in this article are 
included in the article's Creative Commons licence, unless indicated otherwise in a credit line to the material. If material is not included in the article's Creative Commons licence and your intended use is not permitted by statutory regulation or exceeds the permitted use, you will need to obtain permission directly from the copyright holder. To view a copy of this licence, visit http://creativecommons.org/licenses/by$\mathrm{nc} / 4.0 /$.

\section{REFERENCES}

1. Thygesen K, Alpert JS, Jaffe AS, Simoons ML, Chaitman BR, White HD. Third universal definition of myocardial infarction. Circulation. 2012;126: 2020-35.

2. Mahajan VS, Jarolim P. How to interpret elevated cardiac troponin levels. Circulation. 2011;2011: 2350-4.

3. Winchester DE, Kline K, Estel C, Mahtta D, Taasan S, Peacock FW. Associations between cardiac troponin, mortality and subsequent use of cardiovascular services: differences in sex and ethnicity. Open Heart. 2018;5:e000713.

4. Tehrani D, Seto A. Third universal definition of myocardial infarction: update, caveats, differential diagnoses. Clevel Clin J Med. 2013;80:777-86. 